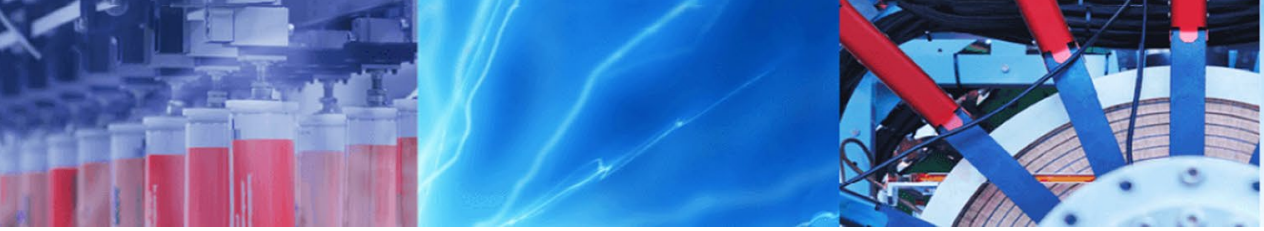

Research Article

\title{
Development of an artificial neural network for the prediction of relative viscosity of ethylene glycol based nanofluids
}

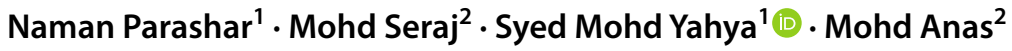

Received: 20 February 2020 / Accepted: 28 July 2020 / Published online: 4 August 2020

(c) Springer Nature Switzerland AG 2020

\begin{abstract}
In this paper, we have developed an artificial neural network (ANN) model for the prediction of the viscosity of ethylene glycol-based nanofluids using data available in the literature. To develop the model, 377 data points were taken from the available literature. The data includes $\mathrm{MgO}, \mathrm{Y}_{3} \mathrm{Al}_{5} \mathrm{O}_{12}, \mathrm{In}_{2} \mathrm{O}_{3}, \mathrm{Ag}, \mathrm{SiO}_{2}, \mathrm{Fe}, \mathrm{Mg}(\mathrm{OH})_{2}, \mathrm{ZnO}, \mathrm{SiC}_{2} \mathrm{Al}_{2} \mathrm{O}_{3}, \mathrm{CeO}_{2}$ and $\mathrm{Ce}_{3} \mathrm{O}_{4}$ nanoparticles. The inputs given to the ANN model were the diameter of the nanoparticles, temperature, and concentration of the nanoparticles, whereas output was the ratio of dynamic viscosity of the nanofluids to that of the base fluid. The ANN model was trained using $80 \%$ of the dataset and the rest of the dataset was used for testing the performance of the developed model. In order to prevent the model from getting overfit, dropout layers were also used. The trial and error method was used to find the optimum model. The optimum model consisted of 2 hidden layers and 45 neurons in both the hidden layers. The developed model shows good performance with the value of mean square error for the training data and test data being 3.9E- 04 and $4.4 \mathrm{E}-04$, respectively. The value of correlation coefficient $(\mathrm{R})$ for the training data and test data was found to be 0.9962 and 0.996 , respectively. Despite the high number of neurons in hidden layers, performance parameters reveal that there is no overfitting in the model. A comparison between the experimental values and the values predicted by the ANN model is also done in this paper.
\end{abstract}

Keywords Nanofluids · Artificial neural network · Ethylene glycol · Viscosity

\section{Introduction}

Nanofluid is a class of fluids in which the fluid is suspended with nanometer-sized particles called the nanoparticles. These nanoparticles can be metallic (pure, oxide, carbide etc.), ceramics, carbon based nanomaterials (carbon nanotubes, diamond etc.), 2 dimensional nanomaterials (graphene, MXene etc.) [1, 2]. Nanofluids exhibits enhanced thermophysical properties due to which they have a wide number of applications such as in automotive industry $[3,4]$, electronics cooling $[5,6]$, solar thermal and photovoltaic systems $[7,8]$ etc. A lot of research has been done in order to determine the parameters affecting the thermophysical and rheological properties (such as thermal conductivity, viscosity etc.) of nanofluids $[9,10]$. It has been found that the parameters such as the nanoparticles size, nanofluid temperature, nanoparticles concentration have the most significant impact on the thermophysical and rheological properties. Moreover, thermal conductivity enhancement is desired as it leads to enhanced heat transfer rate, whereas viscosity enhancement is not desired as it significantly increases the pump work [11, 12]. Hence, it becomes important to determine the viscosity of nanofluids before using it for any specific application.

Determining these properties of nanofluids experimentally is fairly time consuming and costly process [13]. Therefore, it is best to develop correlations that describes the variation of these properties with the parameters that

$\triangle$ Syed Mohd Yahya, smyahya@zhcet.ac.in |'Sustainable Energy and Acoustics Research Lab, Mechanical Engineering Department, AMU, Aligarh 202002, India. ${ }^{2}$ Department of Mechanical Engineering, Integral University, Lucknow 226026, India. 
affects it. Many researchers came up with different models and correlations that can be used to predict the viscosity of nanofluids. However, developing accurate correlations is difficult because of highly non-linear dependency between the variables involved and viscosity. Artificial neural networks (ANNs) can be a more powerful and effective way of predicting the viscosity of nanofluids. ANNs are the computational models that are excellent tools for finding the non-linear and complex relationships between the independent variables and dependent variable(s). Many researchers have employed this technique for predicting the viscosity of various nanofluids. Some of those studies are discussed here.

Toghraie et al. [11] developed an ANN model for the prediction of the viscosity of silver/ethylene glycol nanofluid. The input variables given to the ANN model were temperature and concentration of the silver nanoparticles. The temperature was varied from 25 to $55^{\circ} \mathrm{C}$ and nanoparticles concentration was varied from 0.2 to 2 vol\%. Afrand et al. [14] developed an ANN model for the prediction of the viscosity of MWCNTs/water nanofluid. The input variables given to the ANN model were temperature and concentration of MWCNTs nanoparticles. The temperature was varied from 25 to $65^{\circ} \mathrm{C}$ and nanoparticles concentration was varied from 0 to 1 vol\%. Esfe et al. [15] developed an ANN model for the prediction of the viscosity of $\mathrm{TiO}_{2} /$ water nanofluid. The input variables given to the ANN model were temperature and concentration of $\mathrm{TiO}_{2}$ nanoparticles. The temperature was varied from 283.15 to $343.15 \mathrm{~K}$ and nanoparticles concentration was varied from 1 to 35 mass\%. Longo et al. [16] developed an ANN model for the prediction of the viscosity of oxide based nanofluids. The nanoparticles considered were $\mathrm{Al}_{2} \mathrm{O}_{3}$ and $\mathrm{TiO}_{2}$. The input variables given to the ANN model were temperature, concentration of nanoparticles, nanoparticles diameter, nanoparticles cluster diameter and base fluid type. For $\mathrm{Al}_{2} \mathrm{O}_{3}$ /water nanofluid, temperature was varied from 1 to $40{ }^{\circ} \mathrm{C}$ and nanoparticles concentration was varied from 1 to 4 vol\%. For $\mathrm{TiO}_{2} /$ water nanofluid, temperature was varied from 1 to $40^{\circ} \mathrm{C}$ and nanoparticles concentration was varied from 1 to 6 vol\%. For $\mathrm{TiO}_{2}$ /ethylene glycol and $\mathrm{Al}_{2} \mathrm{O}_{3}$ /ethylene glycol nanofluids, temperature was varied from 0 to $50^{\circ} \mathrm{C}$ and nanoparticles concentration was varied from 0 to 3 vol\%. Vakili et al. [17] conducted experiments to determine the viscosity of the graphene nanoplatelets (GNP)/deionised (DI) water where temperature was varied from 20 to $60^{\circ} \mathrm{C}$ and nanoparticles concentration was varied from 0.025 to 0.1 mass $\%$. Then an ANN model, to predict the viscosity using the experimentally determined values, was also developed.

Derakhshanfard and Mehralizadeh [18] performed experiments to study the effect of $\mathrm{Fe}_{2} \mathrm{O}_{3}, \mathrm{ZnO}, \mathrm{TiO}_{2}, \mathrm{WO}_{3}$ and $\mathrm{NiO}$ nanoparticles on the viscosity of crude oil when temperature was varied from 40 to $100{ }^{\circ} \mathrm{C}$ and nanoparticles concentration was varied from 0.2 to 2 mass $\%$. An ANN model, with the temperature and nanoparticles concentration as input parameters, was also developed using the experimental data. Amani et al. [19] conducted experiments to study the variation of $\mathrm{MnFe}_{2} \mathrm{O}_{4} /$ water nanofluid viscosity under the varying conditions of temperature, nanoparticles concentration and magnetic field. An ANN model was also developed for the prediction of the viscosity of $\mathrm{MnFe}_{2} \mathrm{O}_{4}$ /water nanofluid. The temperature, nanoparticles concentration, and applied magnetic field were given as input variables. The temperature was varied from 20 to $60^{\circ} \mathrm{C}$, nanoparticles concentration was varied from 0.25 to 3 vol\% and applied magnetic field was varied from 100 to $400 \mathrm{G}$. Zhao and $\mathrm{Li}$ [20] conducted experiments to determine the viscosity of alumina-water nanofluid. The temperature was varied from 296 to $313 \mathrm{~K}$ and nanoparticles concentration was varied from 1.31 to 5.92 vol\%. A radial basis neural network (RBF-ANN) model was also developed in order to predict the viscosity of alumina-water. The temperature and nanoparticles concentration were given as inputs to RBF-ANN model. Esfe et al. [13] developed an ANN model for prediction of the viscosity and thermal conductivity of the $\mathrm{Fe} / \mathrm{EG}$ nanofluid. The input variables given to ANN model were temperature, nanoparticles concentration and diameter of nanoparticles, whereas output variables were viscosity and thermal conductivity of Fe/EG nanofluid. The details of these researchers' work who have used ANN to predict the viscosity of nanofluids is given in the Table 1. The input parameters used to develop the ANN model are highlighted in the table.

However, almost all the aforementioned models predict the viscosity values for only single nanoparticles. Moreover, no ANN model has been reported in the literature which can be used to predict the viscosity values for multiple EG based nanofluids. Therefore, in this paper, an ANN model for the prediction of the relative viscosity of ethylene glycol (EG) based nanofluids has been developed. Developing such a model will allow researchers to determine the viscosity of various EG based nanofluids. To develop the model, nanoparticles diameter, temperature and the volume fraction are taken as input variables. Nanoparticles included in the study are $\mathrm{SiO}_{2}, \mathrm{Fe}, \mathrm{Mg}(\mathrm{OH})_{2}, \mathrm{SiC}, \mathrm{ZnO}, \mathrm{Al}_{2} \mathrm{O}_{3}, \mathrm{CeO}_{2}, \mathrm{Co}_{3} \mathrm{O}_{4}, \mathrm{MgO}$, $\mathrm{Ag}, \ln _{2} \mathrm{O}_{3}$ and $\mathrm{Y}_{3} \mathrm{Al}_{5} \mathrm{O}_{12}$. ANNs with different structures were employed and ANN showing the best performance characteristics was selected through the trial and error method. To check the performance of the model, comparison between the ANN predicted values and experimental values was also done.

Forthcoming section includes: data collection, data pre-processing and development of the ANN model, 
Table 1 The work done on the prediction of viscosity of nanofluids by ANN

\begin{tabular}{|c|c|c|c|c|c|}
\hline References & Nanofluid (s) & $\begin{array}{l}\text { Diameter of } \\
\text { nanoparticles } \\
(\mathrm{nm})\end{array}$ & Temperature (K) & Nanoparticles concentration & Remarks \\
\hline [11] & $\mathrm{Ag} / \mathrm{EG}$ & $30-50$ & 298.15-328.15 & $0.25-2$ vol\% & $\mathrm{MSE}^{\mathrm{a}}=0.0012$ max. error $=0.0858$ \\
\hline [14] & MWCNTs/water & & 298.15-338.15 & 0-1 vol\% & $\begin{array}{l}\mathrm{MAPE}^{\mathrm{b}}=0.910 \% \text { Maximum deviation } \\
\text { margin }=0.28 \%\end{array}$ \\
\hline [15] & $\mathrm{TiO}_{2} /$ water & & 283.15-343.15 & 1-35 mass $\%$ & $\begin{array}{l}\text { Maximum percentage of deviation }=2 \% \\
R^{c}=0.9998\end{array}$ \\
\hline \multirow[t]{4}{*}[16]{} & $\mathrm{TiO}_{2} /$ water & $30-50 \pm 10$ & 274.15-313.15 & $1-6$ vol\% & \multirow{4}{*}{$\begin{array}{l}\text { Nanoparticles cluster size were } \\
\text { considered for development of ANN, } \\
\text { MAPE }=1.91 \%, \operatorname{RMSE}^{d}=0.0432\end{array}$} \\
\hline & $\mathrm{Al}_{2} \mathrm{O}_{3} /$ water & $30 \pm 10$ & 274.15-313.15 & $1-4$ vol\% & \\
\hline & $\mathrm{TiO}_{2} / \mathrm{EG}$ & 15 & 273.15-323.15 & $1-3$ vol\% & \\
\hline & $\mathrm{Al}_{2} \mathrm{O}_{3} / \mathrm{EG}$ & 10 & 273.15-323.15 & $1-3$ vol\% & \\
\hline [17] & GNP/DI water & $<2 \mu \mathrm{m}$ & 293.15-333.15 & $0.025-0.1$ mass $\%$ & \multirow[t]{2}{*}{$\mathrm{RMSE}=0.086, \mathrm{MAPE}=0.777$} \\
\hline [18] & $\begin{array}{l}\mathrm{NiO}, \mathrm{WO}_{3}, \mathrm{TiO}_{2} \\
\mathrm{ZnO}, \mathrm{FeO}_{3} / \\
\text { crude oil }\end{array}$ & $10-40$ & 313.15-373.15 & $0.2-2$ mass $\%$ & \\
\hline [19] & $\mathrm{MnFe}_{2} \mathrm{O}_{4} /$ water & 20 & 293.15-333.15 & $0.25-3 \mathrm{vol} \%$ & $\begin{array}{l}\text { Magnetic field }(B) \text { was considered for } \\
\text { ANN development } B=100-400 G \\
M S E=8.56 E-07 R^{2 e}=0.994\end{array}$ \\
\hline$[20]$ & $\mathrm{Al}_{2} \mathrm{O}_{3} /$ water & 30 & $296-313$ & $1.31-5.92$ vol\% & $\mathrm{MAPE}=0.5618 \% \mathrm{R}^{2}=0.999913$ \\
\hline
\end{tabular}

a Mean square error

${ }^{\mathrm{b}}$ Mean average percentage error

cCorrelation coefficient

${ }^{\mathrm{d}}$ Root mean square error

eCoefficient of determination

discussion on the predictions of the ANN model, and comparison of ANN predicted values with experimental values.

\section{Development of artificial neural network}

\subsection{Data collection}

To develop the ANN model, 377 experimental data points were extracted from the literature. The details of the data is given in the Table 2. The input variables to the ANN model were temperature $(T)$, nanoparticle diameter $\left(d_{p}\right)$ and concentration of the nanoparticles $(\phi)$. In the data extracted, temperature varied from 283.15 to $333.15 \mathrm{~K}$, nanoparticles diameter varied from 4 to $100 \mathrm{~nm}$ and nanoparticles concentration varied from 0.05 to 8.2 vol\%.

\subsection{Development of the ANN}

In the present work, we have employed a multilayer perceptron (MLP) neural network model for the prediction of the viscosity of EG based nanofluids. Due to their ability to handle non-linearly dependent complex data, MLPANN are the most commonly used type of ANN models [35]. The algorithm used to train the MLP network was back-propagation which when used in feed forward network, is also known as the feed forward back propagation algorithm [36]. The data contains 12 different nanoparticles, hence to make model able to differentiate between different nanoparticles, numbers have been alloted to different nanoparticles, which are given in Table 3. However, assigning the nanoparticles numbers creates another problem. Model now can assume that there is an ordering between different nanoparticles which is not true and may give poor performance and inaccurate results. To prevent this from happening, data expressed in Table 3 was further processed in a form such that the model not only can differentiate between different nanoparticles but also does not get biased against any nanoparticle on the basis of numbers assigned. Table 4 shows the form in which the number assigned to different nanoparticles are convereted into and eventually fed into the neural network for training process.

To develop the ANN model, whole data was divided into 2 parts with first being the training data which is $80 \%$ of the total dataset and second being the test data which is $20 \%$ of the dataset. The test data was used to evaluate the model performance. The performance of the model on the test data determines whether the model is underfit, overfit or fits the data well [36]. The data was also normalized in 
Table 2 Details of data taken to develop the ANN model

\begin{tabular}{lllllr}
\hline Reference & Nanoparticles & $\mathrm{d}_{\mathrm{p}}(\mathrm{nm})$ & $\phi$ & Temperature $(\mathrm{K})$ & $\begin{array}{c}\text { Number of } \\
\text { data points }\end{array}$ \\
\hline$[21]$ & $\mathrm{MgO}$ & 20 & $1.6-7.2$ vol\% & 298.15 & 4 \\
{$[22]$} & $\mathrm{Y}_{3} \mathrm{Al}_{5} \mathrm{O}_{12}$ & 100 & $1.2-5.8$ vol\% & 298.15 & 4 \\
{$[23]$} & $\mathrm{Ag}$ & 40 & $0.25-2 \mathrm{vol} \%$ & $298.15-328.15$ & 42 \\
{$[24]$} & $\mathrm{SiO}_{2}$ & 10 & $0.5-2.6 \mathrm{vol} \%$ & 298.15 & 5 \\
{$[25]$} & $\mathrm{SiO}_{2}$ & 25 & $0.1-3.0$ vol\% & $303.15-323.15$ & 40 \\
{$[26]$} & $\mathrm{In}_{2} \mathrm{O}_{3}$ & 4 & $0.16-0.81$ vol\% & 298.15 & 5 \\
{$[27]$} & $\mathrm{Fe}$ & $40,70,100$ & $0.125-3.0$ vol\% & $299.15-328.15$ & 72 \\
{$[28]$} & $\mathrm{Mg} \mathrm{OH})_{2}$ & 20 & $0.1-2.0$ vol\% & $297.15-328.15$ & 28 \\
{$[29]$} & $\mathrm{ZnO}$ & 30 & $3.5-10.5 \mathrm{mass} \%$ & $288.15-328.15$ & 25 \\
{$[30]$} & $\mathrm{SiC}_{[31]}$ & 30 & $0.2-1.0$ vol\% & 298.15 & 5 \\
{$[32]$} & $\mathrm{Al}_{2} \mathrm{O}_{3}$ & 43 & $0.5-6.6$ vol\% & $283.15-323.15$ & 56 \\
{$[33]$} & $\mathrm{SiO}_{2}$ & 28.3 & $0.61-8.20$ vol\% & $298.15-333.15$ & 30 \\
{$[34]$} & $\mathrm{CeO}_{2}$ & 20 & $0.05-1.2$ vol\% & $298.15-323.15$ & 36 \\
\hline
\end{tabular}

the range from 0 to 1 to enhance the performance of the model. This was done according to following equation:

$x_{\text {norm }}=\frac{x-x_{\min }}{x_{\max }-x_{\min }}$

where $x_{\text {norm }}, x_{\min }$ and $x_{\max }$ are the normalized value, minimum value and maximum value of the variables.

Figure 1 shows the topology of the ANN model. It has 4 layers, with first layer (green color) being the input layer, second and third layer (blue color) being the hidden layers and fourth layer (red color) being the output layer.

After transforming the data in Table 3 to the form shown in Table 4, we had a total of 15 input variables and one output variable i.e. the ratio of the viscosity of the nanofluid to that of the basefluid. Therefore, the input layer has 15 neurons and the output layer has only 1 neuron. The rectified linear activation (ReL) function and linear function were
Table 4 Final form of nanoparticles numbering fed into the ANN

\begin{tabular}{lllllllllllll}
\hline & $\mathrm{MgO}$ & $\mathrm{Y}_{3} \mathrm{Al}_{5} \mathrm{O}_{12}$ & $\mathrm{Ag}$ & $\mathrm{SiO}_{2}$ & $\mathrm{In}_{2} \mathrm{O}_{3}$ & $\mathrm{Fe}$ & $\mathrm{Mg}(\mathrm{OH})_{2}$ & $\mathrm{ZnO}$ & $\mathrm{SiC}$ & $\mathrm{Al}_{2} \mathrm{O}_{3}$ & $\mathrm{CeO}_{2}$ & $\mathrm{CO}_{3} \mathrm{O}_{4}$ \\
\hline 1 & 1 & 0 & 0 & 0 & 0 & 0 & 0 & 0 & 0 & 0 & 0 & 0 \\
2 & 0 & 1 & 0 & 0 & 0 & 0 & 0 & 0 & 0 & 0 & 0 & 0 \\
3 & 0 & 0 & 1 & 0 & 0 & 0 & 0 & 0 & 0 & 0 & 0 & 0 \\
4 & 0 & 0 & 0 & 1 & 0 & 0 & 0 & 0 & 0 & 0 & 0 & 0 \\
5 & 0 & 0 & 0 & 0 & 1 & 0 & 0 & 0 & 0 & 0 & 0 & 0 \\
6 & 0 & 0 & 0 & 0 & 0 & 1 & 0 & 0 & 0 & 0 & 0 & 0 \\
7 & 0 & 0 & 0 & 0 & 0 & 0 & 1 & 0 & 0 & 0 & 0 & 0 \\
8 & 0 & 0 & 0 & 0 & 0 & 0 & 0 & 1 & 0 & 0 & 0 & 0 \\
9 & 0 & 0 & 0 & 0 & 0 & 0 & 0 & 0 & 1 & 0 & 0 & 0 \\
10 & 0 & 0 & 0 & 0 & 0 & 0 & 0 & 0 & 0 & 1 & 0 & 0 \\
11 & 0 & 0 & 0 & 0 & 0 & 0 & 0 & 0 & 0 & 0 & 1 & 0 \\
12 & 0 & 0 & 0 & 0 & 0 & 0 & 0 & 0 & 0 & 0 & 0 & 1 \\
\hline
\end{tabular}




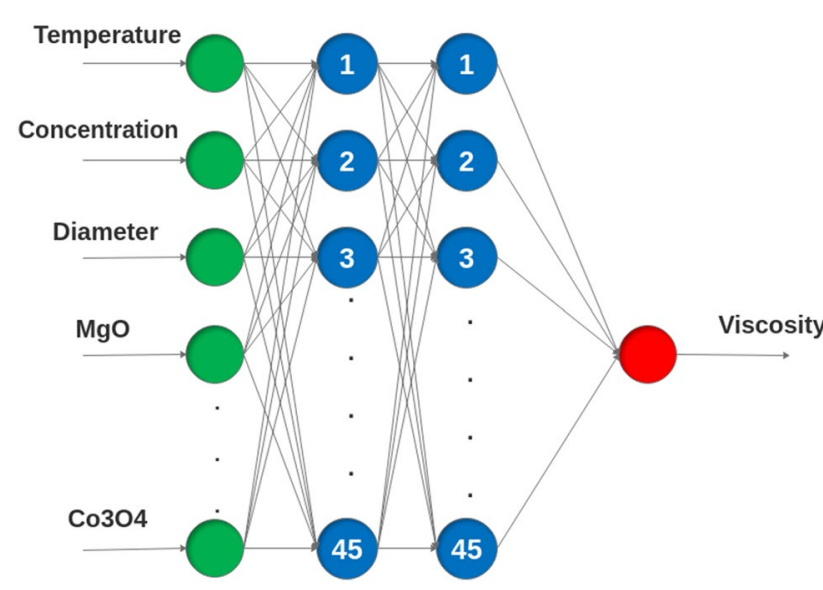

Fig. 1 Topology of the developed optimum ANN model

Table 5 Values of various parameters of the optimum ANN

\begin{tabular}{ll}
\hline Parameters & Optimum value \\
\hline Number of hidden layers & 2 \\
Number of neurons in both the hidden layers & 45 \\
Learning rate & 0.0005 \\
batch size & 200 \\
Number of iterations & 15,000
\end{tabular}

chosen as activation function for hidden layers and output layer, respectively. The model was trained using stochastic gradient descent optimizer and adam optimizer. The model showed better performance when trained using adam optimizer. The developed ANN model was also sensitive to several other parameters. These parameters are shown in Table 5. The optimum value of these parameters was found through the trial and error method. It is also to be noted that to avoid the overfitting of the model due to high number of iterations involved, dropout layers were also used. Performance parameters like mean square error (MSE), mean average percentage error (MAPE), correlation coefficient (R) and deviation (D) were used to evaluate the model performance. The values of these performance parameters shows that there is no overfitting in the model. These performance parameters are defined as follows:

$$
\begin{aligned}
& \text { MSE }=\frac{1}{n} \sum_{i=1}^{n}\left(Y_{\text {exp }, \mathrm{n}}-Y_{\text {pred }, \mathrm{n}}\right)^{2} \\
& \text { MAPE }=\left[\frac{1}{n} \sum_{i=1}^{n}\left|\frac{Y_{\text {exp, } n}-Y_{\text {pred }, \mathrm{n}}}{Y_{\text {exp }, \mathrm{n}}}\right|\right] \times 100
\end{aligned}
$$

Table 6 Values of performance parameters for the optimum ANN

\begin{tabular}{llll}
\hline & Train & Test & All \\
\hline MSE & 0.00039 & 0.000440 & 0.00040 \\
MAPE (\%) & 1.30 & 1.648 & 1.37 \\
R & 0.9962 & 0.996 & 0.996 \\
\hline
\end{tabular}

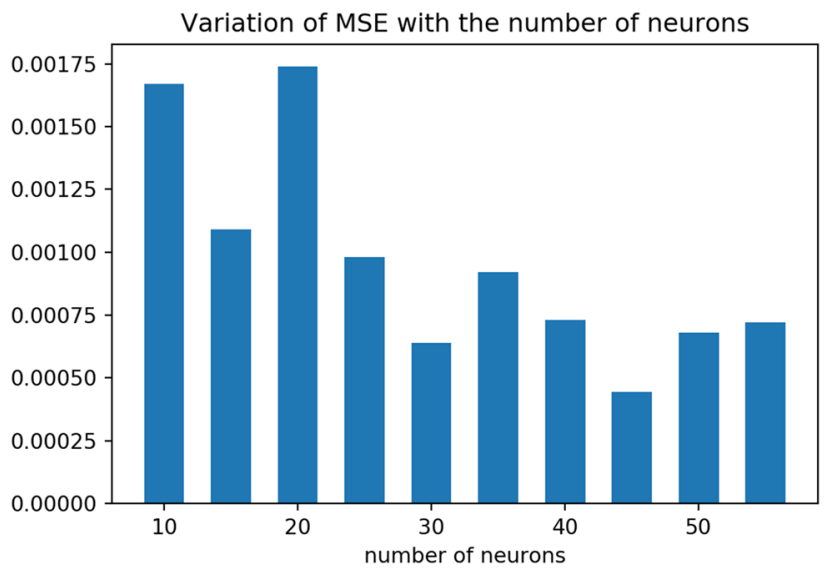

Fig. 2 Plot showing variation of MSE with the number of neurons

$R=\left[\frac{\sum_{i=1}^{n}\left(Y_{\text {pred }, \mathrm{n}}-Y_{\text {pred,avg }}\right)\left(Y_{\text {exp }, \mathrm{n}}-Y_{\text {exp }, \mathrm{avg}}\right)}{\sqrt{\sum_{i=1}^{n}\left(Y_{\text {pred }, \mathrm{n}}-Y_{\text {pred,avg }}\right)^{2} \sum_{i=1}^{n}\left(Y_{\text {exp }, \mathrm{n}}-Y_{\text {exp }, \text { avg }}\right)^{2}}}\right]$

$D=\left(\frac{Y_{\exp }-Y_{\text {pred }}}{Y_{\exp }}\right) \times 100$

where $Y_{\text {exp }}, Y_{\text {pred }} Y_{\text {exp,avg, }} Y_{\text {pred,avg }}$ and $n$ are the experimentally determined values, ANN predicted values, average of experimentally determined values, average of the ANN predicted values, and number of datapoints, respectively.

The optimum values of the performance parameters MSE, MAPE and R for the test data, training data and the whole (i.e train data + test data) data is given in Table 6.

Figure 2 shows the variation of MSE of the test data with number of neurons in both the hidden layers. It shows that the mean square error is least when there are 45 neurons in both the hidden layers. This signifies that the optimum number of neurons in the hidden layers is 45 .

\section{Results and discussion}

Figure 3 shows the variation of the mean square error (MSE) with the number of iterations. A careful analysis of this curve can be helpful in preventing the model from 


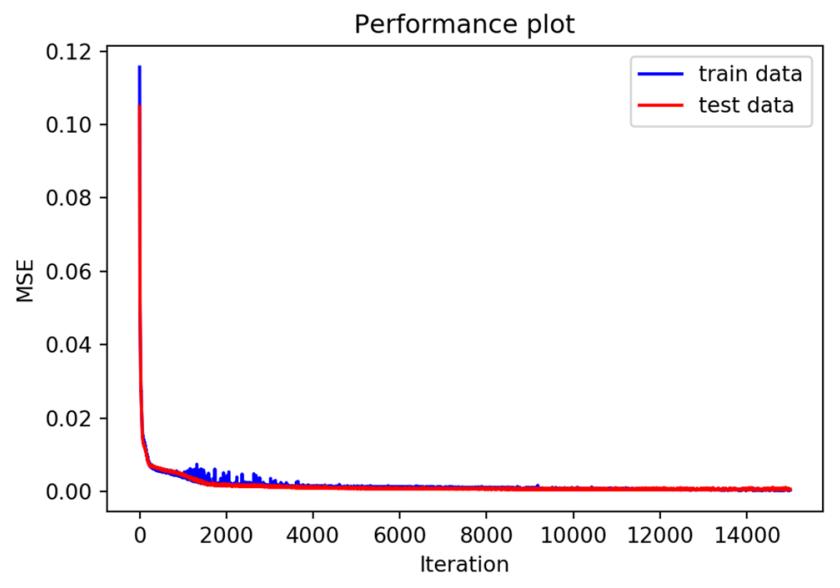

Fig. 3 Plot showing performance curve of the ANN model

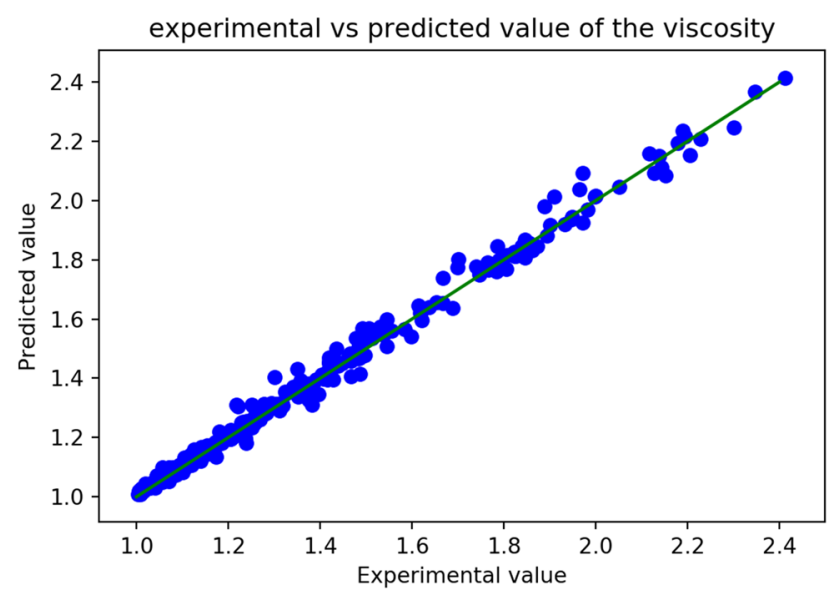

Fig. 4 Plot showing experimental values and ANN predicted values for train data

getting overfit. A well fit model can be obtained by stopping the training process at a point where the value of loss function for test data starts increasing. An increase in the value of loss function for test data signifies that the model has started transisting from a well fit model to an overfit model. As can be seen from the figure, loss function i.e. MSE for both the training data and test data is decreasing rapidly upto several hundreds of iterations, then decreased steadily upto several thousands iterations and then decreased very slowly over next iterations. This shows that the developed ANN model is a well fit model.

Figures 4 and 5 shows the values predicted by the ANN model for every experimentally obtained value. Both the figures shows a line inclined at $45^{\circ}$ to both the axes. The purpose of this line is to show the accuracy of ANN predictions. For an ideal ANN model (i.e with exceptionally low $M S E, R=1$ etc.), all the predicted values will lie on the line. In other words, it can be said that more

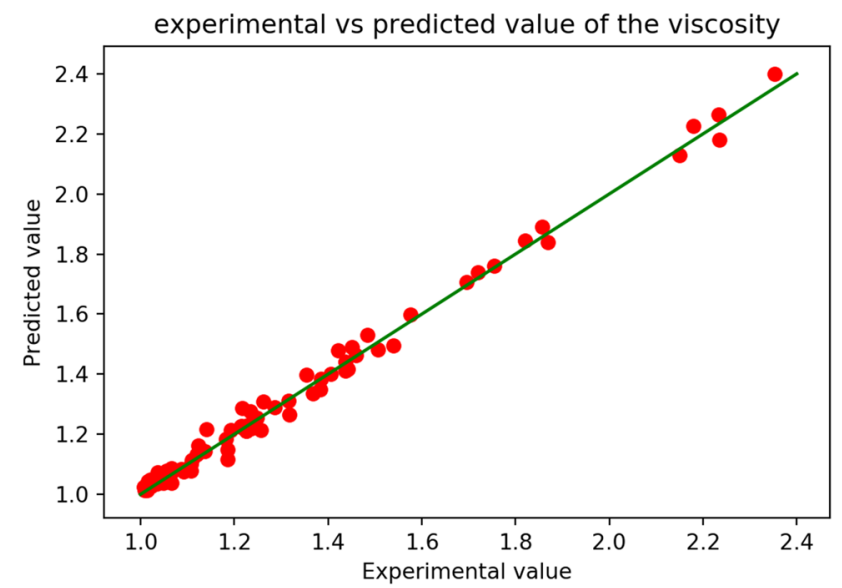

Fig. 5 Plot showing experimental values and ANN predicted values for test data

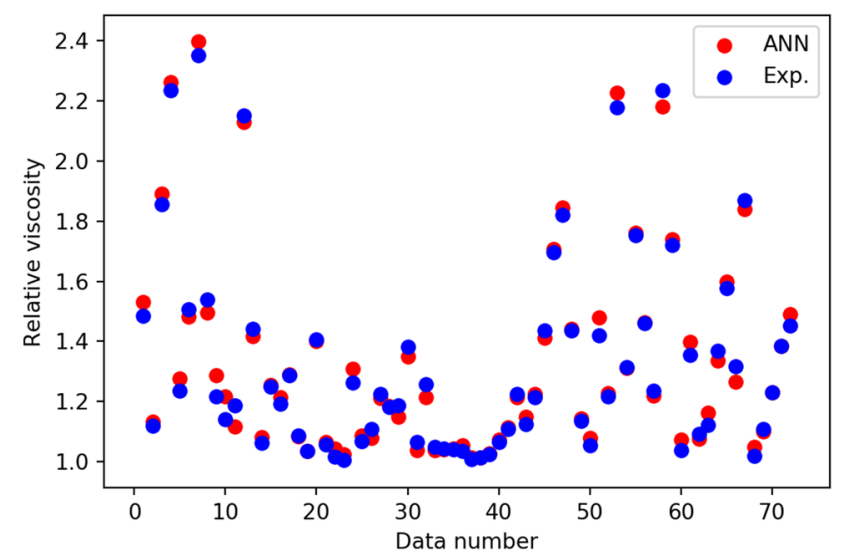

Fig. 6 Plot showing contrast between experimental values and ANN predictions for the test data

the predicted values deviates from the line, lower will be the performance of the ANN model. As can be seen from the Fig. 4, very high number of predictions are lying on the line. However, few predictions are also deviating from the line. This shows that the performance of the ANN model on the train data is good. Figure 5 shows the model performance on test data. As can be seen, very few predictions are deviating from the line. Hence, it can be said that the performance of the model is good on the train data as well as on the test data.

Figure 6 shows the contrast between experimentally determined values and ANN predicted values for test data. It can be seen that the difference between experimentally determined values and ANN predicted values is fairly small, and model is able to predict the values of relative viscosity of the unseen data i.e. test data with good accuracy. It also shows that model has fitted well 


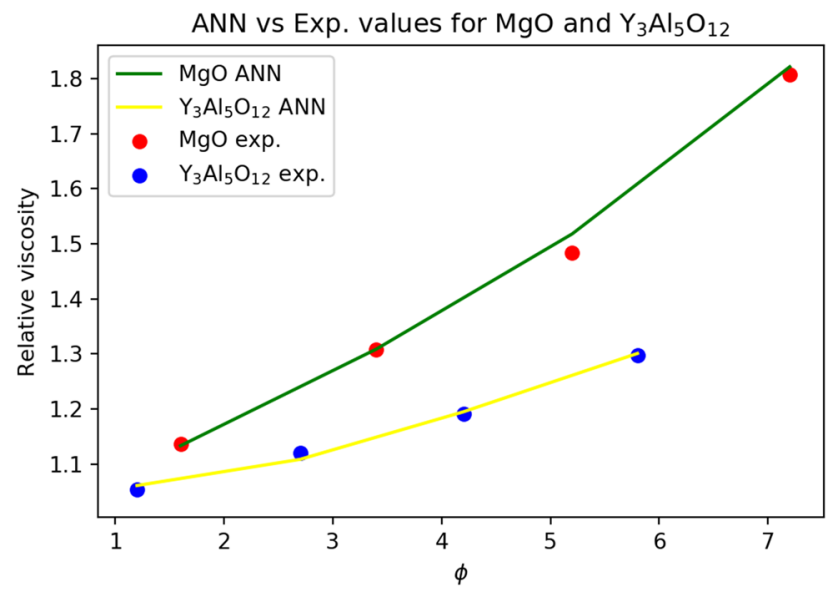

Fig. 7 Plot showing experimental values and ANN predictions for $\mathrm{MgO}$ and $\mathrm{Y}_{3} \mathrm{Al}_{5} \mathrm{O}_{12}$ at different values of volume fractions

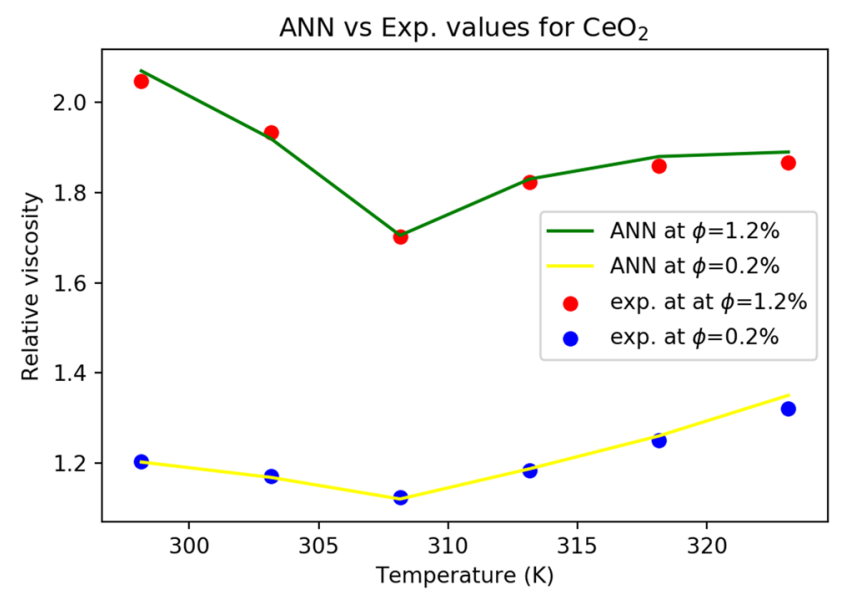

Fig. 8 Plot showing experimental values and ANN prediction for $\mathrm{CeO}_{2}$ with varying temperature at different values of nanoparticles concentrations

on the data and that there is no overfitting in the model despite the high number of iterations.

Figure 7 shows the ability of the ANN to predict the variation of the relative viscosity of $\mathrm{MgO}$ and $\mathrm{Y}_{3} \mathrm{Al}_{5} \mathrm{O}_{12}$ based nanofluids with volume fraction. As can be seen, ANN predictions for all nanoparticles concentration are in excellent agreement with experimentally determined values. Thus, it can be said that the ANN model is able to predict the change in relative viscosity as nanoparticles concentration changes.

Figure 8 shows the ability of the ANN to predict the variation of the relative viscosity of $\mathrm{CeO}_{2}$ based nanofluids with temperature at nanoparticles concentration of 0.2 vol $\%$ and 1.2 vol\%. As can be seen, ANN predictions at all temperature values are in excellent agreement with experimentally determined values. Thus, it can be said that

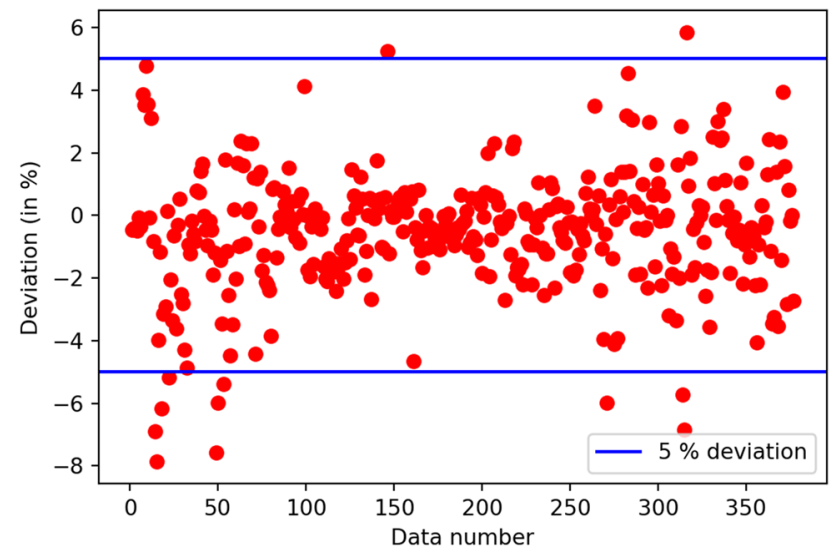

Fig. 9 Plot showing deviation between the experimental values and the ANN predicted values

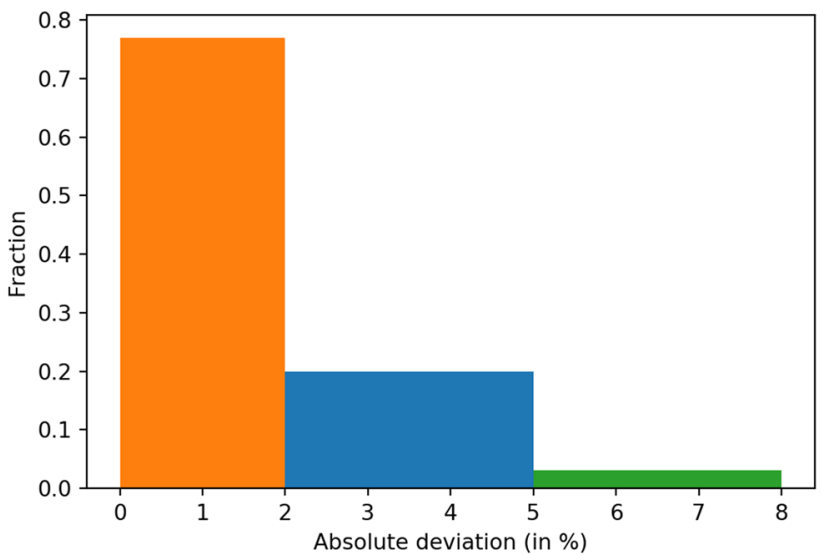

Fig. 10 Bar graph showing fraction of deviation in different absolute deviation range

the ANN model is able to predict the variation in the relative viscosity as temperature varies.

Figure 9 shows the plot of deviation (given by Eq. 5) between the experimentally obtained values and the values predicted by the ANN model. As can be seen from the figure, maximum deviation between experimentally obtained values and ANN predicted values is $-8 \%$. Although majority of deviation points are in the range of $\pm 2 \%$. Furthermore, $97 \%$ of the values predicted by the ANN are within the $5 \%$ deviation range.

The performance of the ANN model is further demonstrated with Fig. 10. Figure shows that $77 \%$ of the deviations (absolute) are in the range of $0-2 \%$. Moreover, $20 \%$ and $3 \%$ of the deviations are in the range of $2-5 \%$ and $5-8 \%$, respectively. This shows that majority of the ANN predictions are in excellent agreement with experimental values.

Based on the values of several statistical parameters and graphs presented, it can be said that the model 
developed in this study is able to predict the values of relative viscosity of EG based nanofluids with good accuracy. It was also shown that despite the high number of iterations and neurons in both the hidden layers, there is no overfitting in the developed ANN model. This may be attributed to the use of dropout layers. This may also be attributed to more complexity of the data which is because of high number of nanoparticles considered in the study. It is also worth noting that the developed model can only be used to determine the relative viscosity of EG nanofluids based on the nanoparticles that were considered in the study.

\section{Conclusion}

This work deals with the development of an artificial neural network to predict the relative viscosity of multiple ethylene glycol-based nanofluids. In order to develop the ANN model, 377 experimental data were taken from 14 research articles available in the literature. These 377 experimental data includes 12 different nanoparticles. The nanoparticles diameter, temperature of the nanofluid and volumetric concentration of the nanoparticles were given as inputs to the ANN model. The optimum ANN topology was found through the trial and error method. To avoid the overfitting due to high number of iterations involved, dropout layers were also used. Furthermore, in order to keep check on overfitting, values of loss function for test data and train data was carefully observed. The optimum model thus developed, had 2 hidden layers and 45 neurons in each of the hidden layers. The values of MSE, MAPE and R for the test data and train data were found to be $0.00044,1.648 \%$ and 0.996 , and $0.00039,1.3$ and 0.9962 , respectively. Moreover, $77 \%$ of the deviations were found to be in the range of $\pm 2 \%$. The performance parameters shows that the ANN is able to predict the values of the relative viscosity with good precision.

The developed model can only be used to predict the values of relative viscosity of the nanofluids considered for model development. Furthermore, it can only be used for range described in the Table 2. Future work can focus on the development of more accurate soft computing models for ethylene glycol based nanofluid while also incorporating more types of nanoparticles. The same approach can also be used for various important heat transfer fluids. Furthermore, more number of input parameters that affects the viscosity of nanofluids can be considered for model development.

\section{Compliance with ethical standards}

Conflict of interest The authors declare that they have no conflict of interest.

\section{References}

1. Sajid MU, Ali HM (2018) Thermal conductivity of hybrid nanofluids: a critical review. Int J Heat Mass Transf 126:211-34

2. Aslfattahi N, Saidur R, Arifutzzaman A, Sadri R, Bimbo N, Sabri MFM, Maughan PA, Bouscarrat L, Dawson RJ, Said SM, Goh BT, Sidik NAC (2020) Experimental investigation of energy storage properties and thermal conductivity of a novel organic phase change material/MXene as A new class of nanocomposites. J Energy Storage 27:101115

3. Xian HW, Sidik NAC, Najafi G (2018) Recent state of nanofluid in automobile cooling systems. J Therm Anal Calorim 135:981-1008

4. Seraj M, Yahya SM, Badruddin IA, Anqi AE, Asjad M, Khan ZA (2020) Multi-response optimization of nanofluid-based I.C. engine cooling system using fuzzy PIV method. Processes 8:30

5. Bahiraei M, Heshmatian S (2018) Electronics cooling with nanofluids: a critical review. Energy Convers Manag 172:438-56

6. Selvaraj V, Krishnan H (2020) Synthesis of graphene encased alumina and its application as nanofluid for cooling of heatgenerating electronic devices. Powder Technol 363:665-75

7. Elsheikh AH, Sharshir SW, Mostafa ME, Essa FA, Ali MKA (2018) Applications of nanofluids in solar energy: a review of recent advances. Renew Sustain Energy Rev 82:3483-502

8. Aslfattahi N, Samylingam L, Abdelrazik AS, Arifutzzaman A, Saidur R (2020) MXene based new class of silicone oil nanofluids for the performance improvement of concentrated photovoltaic thermal collector. Sol Energy Mater Sol Cells 211:110526

9. Ahmadi MA, Mirlohi A, Nazari MA, Ghasempour R (2018) A review of thermal conductivity of various nanofluids. J Mol Liq 265:181-8

10. Murshed SMS, Estelle $P$ (2017) A state of the art review on viscosity of nanofluids. Renew Sustain Energy Rev 76:1134-52

11. Toghraie D, Sina N, Jolfaei NA, Hajian M, Afrand M (2019) Designing an artificial neural network (ANN) to predict the viscosity of Silver/Ethylene glycol nanofluid at different temperatures and volume fraction of nanoparticles. Physica A 534:122142

12. Yahya SM, Asjad M, Khan ZA (2019) Designing an artificial neural network (ANN) to predict the viscosity of silver/ethylene glycol nanofluid at different temperatures and volume fraction of nanoparticles. Mater Res Express 6:0850a1

13. Esfe MH, Saedodin S, Sina N, Afrand M, Rostami S (2015) Designing an artificial neural network to predict thermal conductivity and dynamic viscosity of ferromagnetic nanofluid. Int Commun Heat Mass Transf 68:50-7

14. Afrand $M$, Nadooshan $A A$, Hassani $M$, Yarmand $H$, Dahari $M$ (2016) Predicting the viscosity of multi-walled carbon nanotubes/water nanofluid by developing an optimal artificial neural network based on experimental data. Int Commun Heat Mass Transf 77:49-53

15. Esfe $M H$, Ahangar MRH, Rejvani M, Toghraie D, Hajmohammad MH (2016) Designing an artificial neural network to predict dynamic viscosity of aqueous nanofluid of $\mathrm{TiO}_{2}$ using experimental data. Int Commun Heat Mass Transf 75:192-6

16. Longo GA, Zilio C, Ortombina L, Zigliotto M (2017) Application of artificial neural network (ANN) for modeling oxide-based nanofluids dynamic viscosity. Int Commun Heat Mass Transf 83:8-14 
17. Vakili M, Khosrojerdi S, Aghajannezhad P, Yahyaei M (2017) A hybrid artificial neural network-genetic algorithm modeling for viscosity estimation of graphene nanoplatelets nanofluid using experimental data. Int Commun Heat Mass Transf 82:40-8

18. Derakhshanfard F, Mehralizadeh A (2018) Application of artificial neural networks for viscosity of crude oil-based nanofluids containing oxides nanoparticles. J Pet Sci Eng 168:263-72

19. Amani M, Amani P, Kasaeian A, Mahian O, Pop I, Wongwises S (2017) Modeling and optimization of thermal conductivity and viscosity of $\mathrm{MnFe}_{2} \mathrm{O}_{4}$ nanofluid under magnetic field using an ANN. Sci Rep 7:17369

20. Zhao N, Li Z (2017) Experiment and artificial neural network prediction of thermal conductivity and viscosity for alumina-water nanofluids. Materials 10:552

21. Żyla G (2017) Viscosity and thermal conductivity of MgO-EG nanofluids. J Therm Anal Calorim 129:171-80

22. Żyla G (2015) Thermophysical properties of ethylene glycol based yttrium aluminum garnet $\left(\mathrm{Y}_{3} \mathrm{Al}_{5} \mathrm{O}_{12}-\mathrm{EG}\right)$ nanofluids. Int J Heat Mass Transf 92:751-6

23. Zadeh AD, Toghraie D (2018) Experimental investigation for developing a new model for the dynamic viscosity of silver/ ethylene glycol nanofluid at different temperatures and solid volume fractions. J Therm Anal Calorim 131:1449-61

24. Żyla G, Fal J (2017) Viscosity, thermal and electrical conductivity of silicon dioxide-ethylene glycol transparent nanofluids: an experimental studies. Thermo Acta 650:106-13

25. Akbari M, Afrand M, Arshi A, Karimipour A (2017) An experimental study on rheological behavior of ethylene glycol based nanofluid: proposing a new correlation as a function of silica concentration and temperature. J Mol Liq 233:352-7

26. Żyla G, Wanic M, Malicka M, Fal J (2019) Dynamic viscosity of indium oxide-ethylene glycol $\left(\ln _{2} \mathrm{O}_{3}-E G\right)$ nanofluids: an experimental investigation. Acta Physica Pol A 135:1290-3

27. Esfe MH, Saedodin S, Mahian O, Wongwises S (2014) Efficiency of ferromagnetic nanoparticles suspended in ethylene glycol for applications in energy devices: Effects of particle size, temperature, and concentration. Int Commun Heat Mass Transf 58:138-46

28. Esfe MH, Saedodin S, Asadi A, Karimipour A (2015) Thermal conductivity and viscosity of $\mathrm{Mg}(\mathrm{OH})_{2}$-ethylene glycol nanofluids. J Therm Anal Calorim 120:1145-9

29. Li H, Wang L, He Y, Zhu J, Jiang B (2014) Experimental investigation of thermal conductivity and viscosity of ethylene glycol based ZnO nanofluids. Appl Therm Engg 88:363-8

30. Li X, Zou C, Wang T, Lei X (2015) Rheological behavior of ethylene glycol-based SiC nanofluids. Int J Heat Mass Transf 84:925-30

31. Pastoriza-Gallego MJ, Lugo L, Legido JL, Piñeiro MM (2011) Thermal conductivity and viscosity measurements of ethylene glycol-based $\mathrm{Al}_{2} \mathrm{O}_{3}$ nanofluids. Nanoscale Res Lett 6:221

32. Rudyak VY, Dimov SV, Kuznetsov VV (2013) On the dependence of the viscosity coefficient of nanofluids on particle size and temperature. Tech Phys Lett 39:779-82

33. Saeedi AH, Akbari M, Toghraie D (2018) An experimental study on rheological behavior of a nanofluid containing oxide nanoparticle and proposing a new correlation. Physica E 99:285-93

34. Mariano M, Pastoriza-Gallego MJ, Lugo L, Mussari L, Piñeiro MM (2015) $\mathrm{Co}_{3} \mathrm{O}_{4}$ ethylene glycol-based nanofluids: Thermal conductivity, viscosity and high pressure density. Int J Heat Mass Transf 85:54-60

35. Ahmadloo E, Azizi S (2016) Prediction of thermal conductivity of various nanofluids artificial neural network. Int Commun Heat Mass Transf 74:69-75

36. Parashar N, Aslfattahi N, Yahya SM, Saidur R (2020) An artificial neural network approach for the prediction of dynamic viscosity of MXene-palm oil nanofluid using experimental data. J Therm Anal Calorim. https://doi.org/10.1007/s10973-020-09638-3

Publisher's Note Springer Nature remains neutral with regard to jurisdictional claims in published maps and institutional affiliations. 